\title{
Low Viscosity Processing using Hybrid CNT-coated Silica Particles to Form Electrically Conductive Epoxy Resin Composites
}

DOI:

10.1016/j.polymer.2016.06.009

\section{Document Version}

Accepted author manuscript

Link to publication record in Manchester Research Explorer

Citation for published version (APA):

Wilkinson, A., Kinloch, I., \& Othman, R. (2016). Low Viscosity Processing using Hybrid CNT-coated Silica Particles to Form Electrically Conductive Epoxy Resin Composites. Polymer, 98, 32-38.

https://doi.org/10.1016/j.polymer.2016.06.009

\section{Published in:}

Polymer

\section{Citing this paper}

Please note that where the full-text provided on Manchester Research Explorer is the Author Accepted Manuscript or Proof version this may differ from the final Published version. If citing, it is advised that you check and use the publisher's definitive version.

\section{General rights}

Copyright and moral rights for the publications made accessible in the Research Explorer are retained by the authors and/or other copyright owners and it is a condition of accessing publications that users recognise and abide by the legal requirements associated with these rights.

\section{Takedown policy}

If you believe that this document breaches copyright please refer to the University of Manchester's Takedown Procedures [http://man.ac.uk/04Y6Bo] or contact uml.scholarlycommunications@manchester.ac.uk providing relevant details, so we can investigate your claim.

\section{OPEN ACCESS}




\title{
Low Viscosity Processing using Hybrid CNT-coated Silica Particles to Form \\ Electrically Conductive Epoxy Resin Composites \\ Arthur N. Wilkinson", Ian A. Kinloch and Raja N. Othman ${ }^{\dagger}$
}

\section{North West Composites Centre, School of Materials, The University of Manchester, Manchester, M13 9PL, United Kingdom.}

\begin{abstract}
Hybrid particles of multiwall carbon nanotubes (CNTs) grafted onto silica gel were shown to provide a low viscosity processing route to forming electrically-conductive epoxy resin composites. Rheological studies showed the viscoelastic shear moduli of epoxy resin suspensions containing these particles (named SG6_3) remained within the same order of magnitude as that of the neat resin at $\leq 5 \mathrm{wt} \%$ loading (containing up to $1.65 \mathrm{wt}$ \% of grafted CNTs). Whereas, the addition of $1.65 \mathrm{wt} \%$ of discrete (nongrafted) CNTs into the same resin increased shear moduli by up to seven orders of magnitude. The complex viscosities of suspensions containing $\leq 5 \mathrm{wt} \%$ of SG6_3 remained essentially unchanged, whereas an increase of up to five orders of magnitude resulted upon the addition of $1.65 \mathrm{wt} \%$ of nongrafted CNTs. Whilst rheological studies showed SG6_3 did not form a percolated network at levels $\leq 5$ wt.\%, addition of only 2 wt.\% (containing $0.66 \mathrm{wt} . \% \mathrm{CNT}$ ) was found to form an electrically-conductive percolated network in an epoxy resin composite with conductivity $\sim 10^{-4} \mathrm{~S} / \mathrm{m}$.
\end{abstract}

Keywords: Carbon nanotubes; Hybrid particles; Epoxy resin;

\section{Introduction}

The potential benefits offered by incorporation of carbon nanotubes (CNTs) into polymer composites [1, 2] are often limited by the large increases in viscosity that occur upon the addition of only a few volume percentage of nanotubes. This limits the use of CNTS in structural applications at useful volume fractions [1] and even the lower loadings required for functional applications can create difficulties for processing [3]. Approaches used to improve the dispersion of CNTs in polymer matrices include chemical functionalization, cutting of the nanotubes, in situ polymerization, and enhanced physical blending [4]. An alternative method to mixing nanotubes directly into the matrix is to attach the nanotubes to host particles which are subsequently introduced into the matrix. The most commonly used approach to produce such hybrid particles is to grow the nanotubes directly on the host using catalytic vapour

\footnotetext{
* Corresponding author. Tel: +44 1613065691. Email address: Arthur.Wilkinson@ manchester.ac.uk (A.N. Wilkinson). ${ }^{\dagger}$ Current address; Department of Mechanical Engineering, National Defence University of Malaysia, Kem Sungai Besi, 57000 Kuala Lumpur, Malaysia
} 
deposition (CVD), and this has been reported for a wide range of hosts; including fibres of carbon [5, 6], silica [7], and alumina [8] and particles of silica [9-12], alumina $\left(\mu \mathrm{Al}_{2} \mathrm{O}_{3}\right)$ [13], carbon black [14] and stainless steel [15]. However, a detailed rheological study of suspensions containing hybrid particulateCNT particles has yet to be reported.

A previous publication from this study [16] reported the synthesis and characterisation of hybrid particles produced by the direct growth of multiwall carbon nanotubes (MWCNTs) onto spherical silica-gel particles of approximately $40 \mu \mathrm{m}$ diameter using floating catalyst CVD; and the ability of these hybrid particles to form an electrically-conducting percolated network was demonstrated in composites with poly(vinyl alcohol). The overall aims of this study were to develop hybrid CNT-based particles that are: firstly, easily dispersed in polymer matrices to form stable electrically-conductive percolated networks, in that they are resistant to the shearing forces generated during polymer processing; and secondly do not generate a significant increase in the viscosity of the polymer matrix, a common problem encountered with CNT-polymer composites. To show whether these aims are realised using the hybrid particles developed in our previous study, this paper presents a study of the rheological and electrical properties of epoxy resin composites containing hybrid silica-CNT particles.

\section{Experimental}

\subsection{Materials and Sample Preparation}

The silica gel (SG)-CNT hybrid particles chosen for this study (SG6_3, see Figure 1) were synthesized [16] under optimized conditions of 3 hours reaction time at a reaction temperature of $760{ }^{\circ} \mathrm{C}$ using toluene and ferrocene as the carbon source and catalyst precursor, respectively. Thermogravimetric analysis (TGA) showed the resultant yield on the SG substrates was $33.6 \pm 0.4 \mathrm{wt} . \%$ of grafted CNT with a mean tube diameter measured by TEM of $13 \pm 4 \mathrm{~nm}$.

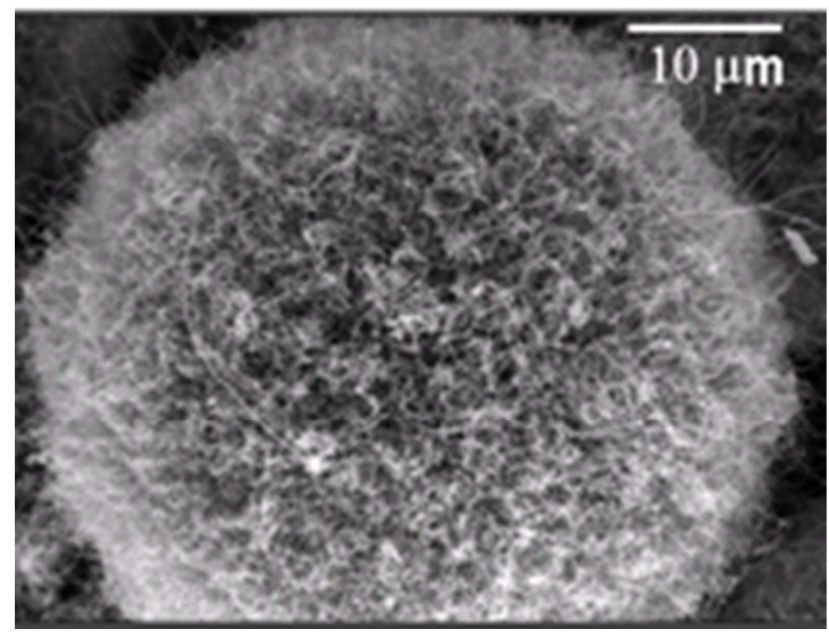

Figure 1. SEM image of a typical SG6_3 hybrid silica gel (SG)-CNT particle. 
Araldite ${ }^{\circ}$ LY556 epoxy resin (Huntsman) was used as the suspension medium to study the rheological properties of SG6_3 suspensions; produced by adding various loadings $(0.5,1,2$, and 5 wt. \%) to the degassed resins, followed by stirring at $2000 \mathrm{rpm}$ at room temperature for an hour. Using the yield of CNT from TGA [16], the CNT addition at each SG6_3 loading was calculated as 0.17, 0.34, 0.66, and 1.65 wt.\%, respectively. For comparison, a range of suspensions (designated as NC) containing nongrafted MWCNTs was prepared under the same conditions and at the same CNT contents using a commercially available grade of MWCNTs (Nanocyl ${ }^{\mathrm{TM}}$ NC 7000 [17]). The dispersion of the hybrid particles in the resin suspensions was viewed under an Olympus BH-2 optical microscope fitted with a x5 objective lens.

For the preparation of composites; an amine hardener Aradur® XB 3473 (Huntsman), a mixture of 80 $92 \%$ diethyltoluenediamine and 4-10\% 1,2- diaminocyclohexane, was added to the mixtures at a constant weight ratio of 100:23 (resin:hardener) as recommended by the manufacturer. The mixtures were stirred for an hour at $2000 \mathrm{rpm}$ before being cast into moulds and cured at $140{ }^{\circ} \mathrm{C}$ for 8 hours to form small plaques $\approx 10 \mathrm{~mm}$ thick.

\subsection{Rheological and Electrical Measurements}

A Thermo Scientific MARS II rheometer system was used to perform rheological measurements on the epoxy suspensions. All measurements were performed at $25^{\circ} \mathrm{C}$ using $35 \mathrm{~mm}$ parallel plates with a 0.5 mm gap. In rotational mode, the shear rate $(\dot{\gamma})$ was increased stepwise $\left(0.005-1000 \mathrm{~s}^{-1}\right)$ and held at each step for $60 \mathrm{~s}$. Under oscillatory shear; a strain $(\gamma)$ sweep $(0.5-500 \%$ strain $)$ was first conducted to determine the linear viscoelastic region (LVR). Once this region was identified frequency-sweep testing $(0.5-100 \mathrm{rad} / \mathrm{s})$ was performed within the LVR, at a constant strain of $1 \%$.

The impedance values of the composites were measured using an Impedance Analysis Interface/NumetriQ PSM1735. A frequency range of 1 to $10^{6} \mathrm{~Hz}$ was applied, at a voltage amplitude of $1.0 \mathrm{~V}$. For measurements the composite plaques were cut into specimens of approximately $40 \mathrm{x} 40 \mathrm{~mm}$. After polishing, silver paint was applied on two opposing cut faces and wires connected to these electrodes using a conductive silver-loaded epoxy adhesive (RS Components). An average of at least five measurements was taken for each sample 


\section{Results and Discussion}

\subsection{Dispersion of SG6_3 Hybrid Particles}

Figure 2 shows a typical optical micrograph of the dispersion achieved in a suspension of 5 wt. $\%$ of SG6_3 within the epoxy resin. During their preparation striking differences were observed between the SG6_3 and NC suspensions. For example, the former flowed easily from the jars in which they were mixed even when the loading was increased to $5 \mathrm{wt} \%$ (equivalent to $1.65 \mathrm{wt}$. \% of CNT). These suspensions were also quite stable, and upon tilting the jars after standing for 24 hours no obvious sedimentation was observed. In contrast, a spatula was required to transfer all of the NC suspensions, even the lowest loading of $0.17 \mathrm{wt}$. \%. In the case of $1.65 \mathrm{wt} \% \mathrm{CNT}$ loading, in contrast to the equivalent SG6_3 suspension (5 wt.\%), the NC suspension did not flow within ten minutes of turning the jar upside down.

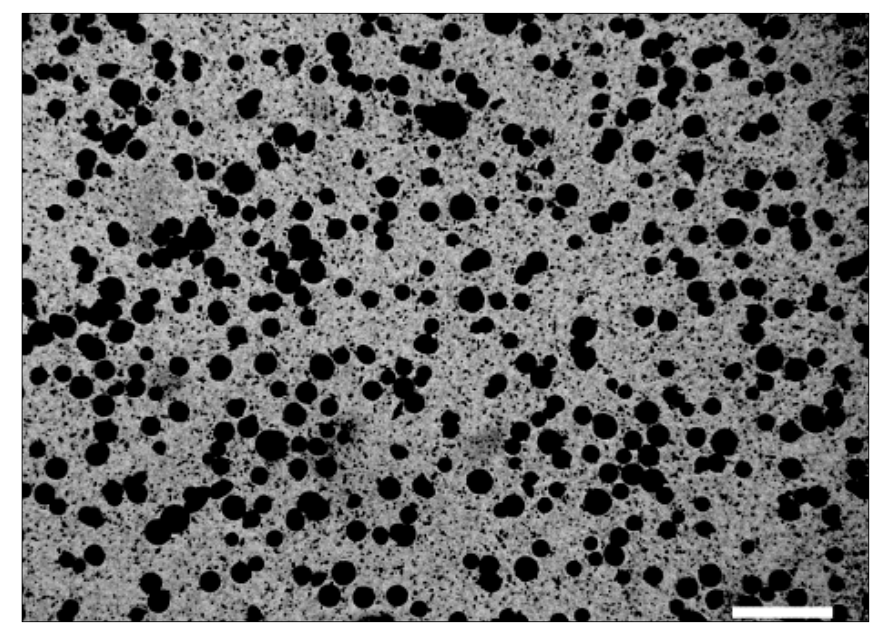

Figure 2. Typical optical micrograph showing a suspension of 5 wt.\% of SG6_3 hybrid particles (1.65 wt. \% of grafted CNTs) in epoxy resin. The scale bar is $200 \mu \mathrm{m}$.

\subsection{Steady Shear Properties}

Figures $3 \mathrm{a}$ and $3 \mathrm{~b}$ show shear viscosity data for all the suspensions as a function of shear rate $(\dot{\gamma})$ and shear stress $(\tau)$, respectively. In Figure 3a, the flow curves of the neat LY556 epoxy resin and the SG6_3 suspensions show equivalent behaviour; displaying Newtonian regions up to $200 \mathrm{~s}^{-1}$ followed by a degree of shear thinning at higher shear rates. In contrast, the two NC suspensions containing discrete, nongrafted CNT exhibit viscosities that are between 1 and 2 orders of magnitude higher at $10^{-1} \mathrm{~s}^{-1}$ and which decrease sharply as the shear rate increases. Similar large increases in viscosity at low shear rates resulting from CNT addition have been observed for suspensions in other epoxy resins [18-21] and water [22], and are attributed to the formation of a percolated network between the CNTs. As the shear rate was increased to $>200 \mathrm{~s}^{-1}$, the viscosities of the NC suspensions decrease and approach those of the epoxy and the SG6_3 suspensions; behaviour indicative of the break-up of the CNT network [18, 20]. 


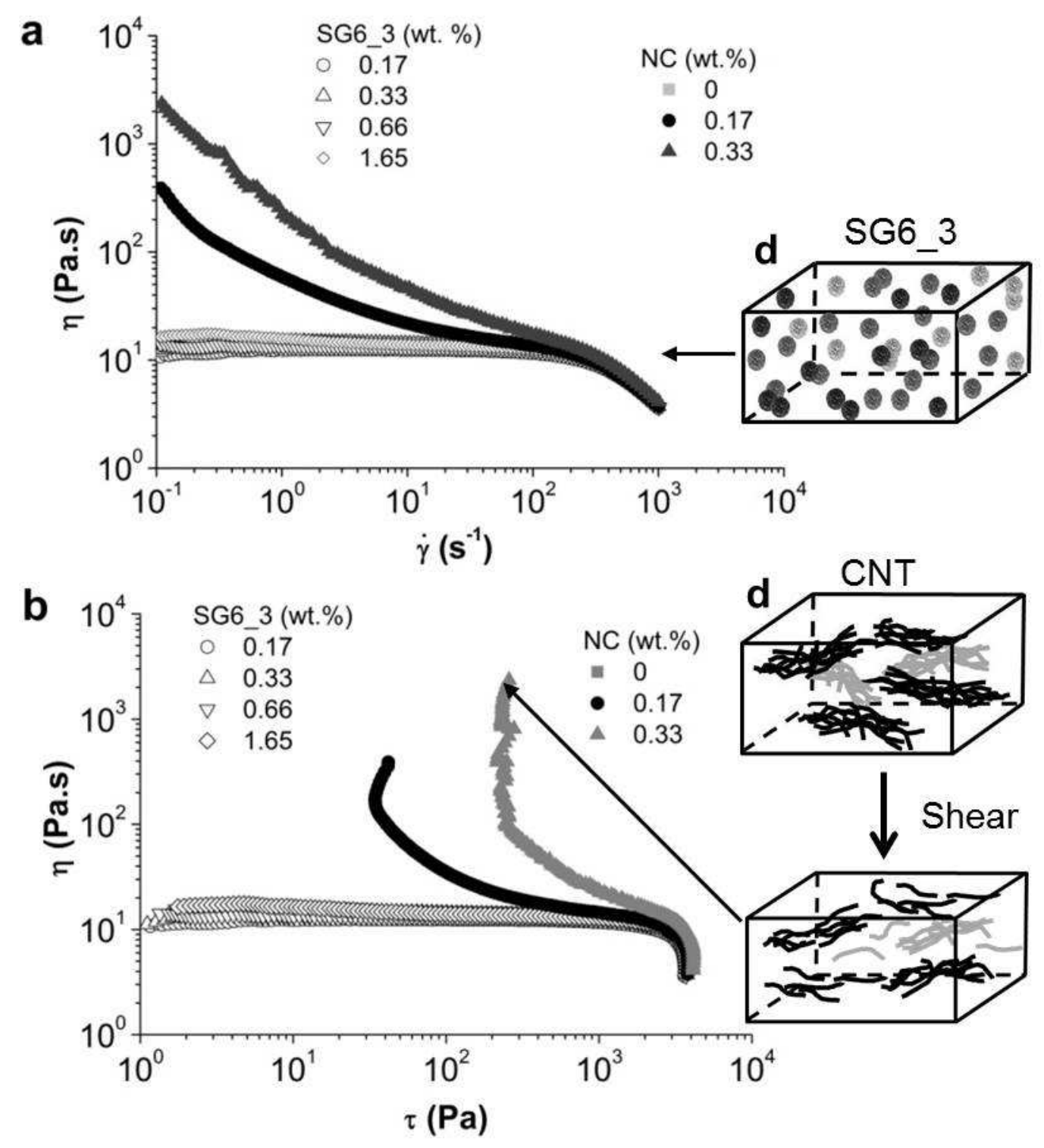

Figure 3. Steady shear viscosity data for the epoxy resin and the SG6_3 and NC suspensions as a function of (a) shear rate and (b) shear stress. The wt. \% shown is that of the grafted CNT in the suspension. The graphics (d) illustrate the particle arrangements in the suspensions for SG6_3, showing a dispersed and well distributed arrangement with predominantly isolated particles which remains essentially unchanged under steady shear up to $200 \mathrm{~s}^{-1}$, and CNT, showing a percolated network of CNT aggregates which begins to break up under steady shear.

The shear viscosity versus shear stress flow curves in Figure $3 b$ show the epoxy resin and the SG6_3 suspensions to display stable Newtonian behaviour over more than three decades of stress (until $\tau=3$ $\mathrm{kPa}$ ). In contrast, the viscosities of the NC suspensions are initially up to two orders of magnitude higher than the SG6_3 suspensions. The viscosity is then observed to decrease by up to two decades while the stress remained essentially constant, before flow initiates at apparent yield stresses of $\approx 40 \mathrm{~Pa}$ and $\approx 250 \mathrm{~Pa}$ 
for the 0.17 and $0.33 \mathrm{wt} . \%$ loadings, respectively. This behaviour is once again indicative of the break-up of the CNT network, and similar observations have been reported for aqueous [22] and other epoxy [21] CNT suspensions. In contrast, the grafted CNTs of the SG6_3 particles remain strongly attached to the substrate and are relatively short. Therefore the degree of inter-tube interaction between CNTs on neighbouring SG6_3 particles is negligible, preventing the formation of an elastic, percolated network.
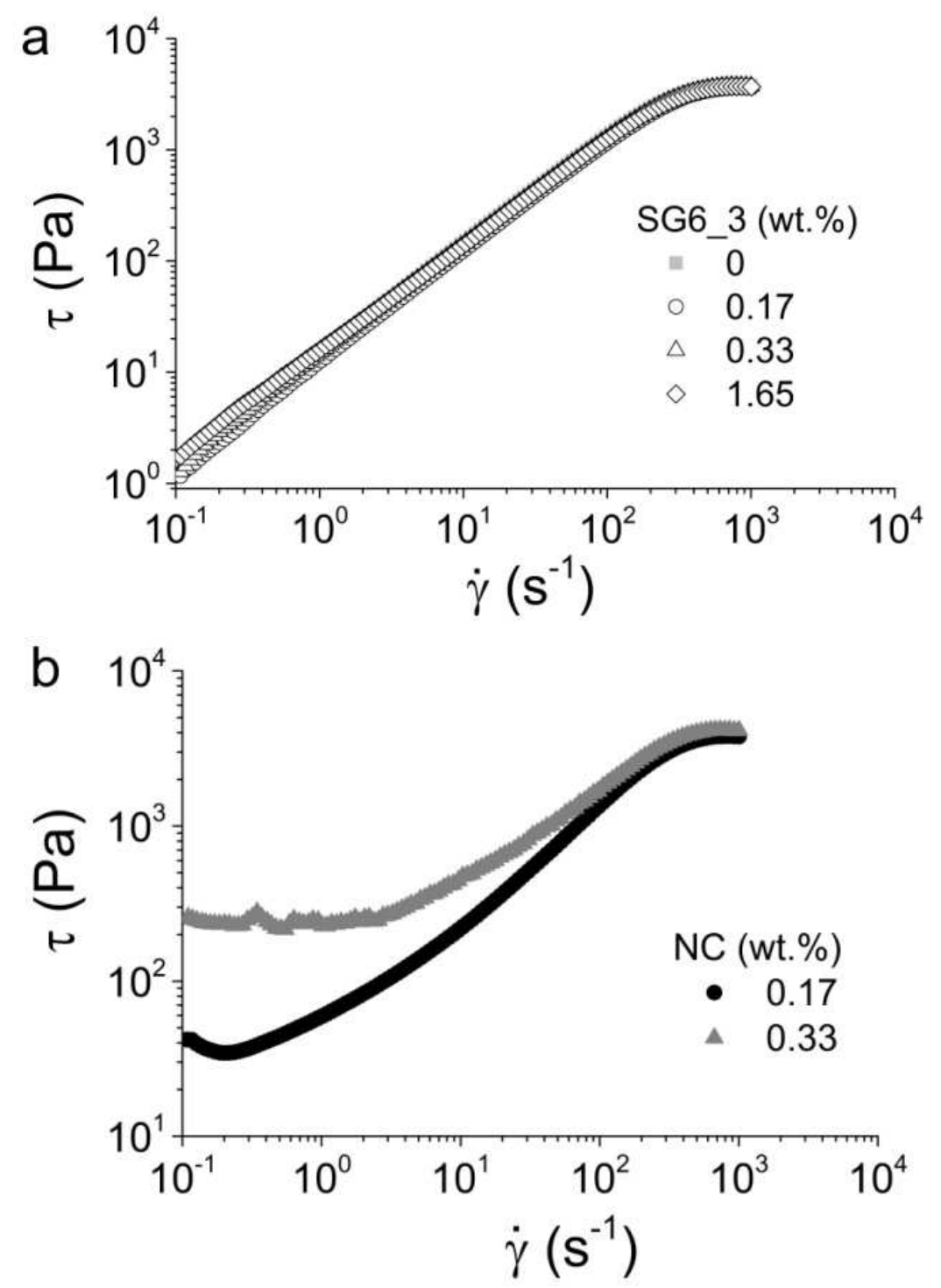

Figure 4: Shear stress-shear rate flow curves for (a) the epoxy resin and SG6_3 suspensions and (b) NC suspensions. The wt. \% shown is that of the grafted CNT in the suspension.

Shear stress versus shear rate flow curves for the resin and the SG6_3 suspensions are shown in Figure 4a. After exceeding a small yield value the stress increases linearly with the applied shear rate until approximately $200 \mathrm{~s}^{-1}$, indicating that viscosity is constant. This essentially linear relationship was also observed in Figure 3a, where the viscosity remained constant at shear rates $<200 \mathrm{~s}^{-1}$. In the case of NC suspensions (Fig 4b), a short region of constant stress at low shear rate is observed followed by increasing stress at higher shear rates. 
The flow curves in Figure 4a exhibit a small yield stress followed by Newtonian behaviour, and therefore the data were fitted to the Bingham plastic, or yield-Newtonian, model [23]:

$$
\tau=\tau_{y}+\eta_{p} \dot{\gamma}
$$

Where $\tau_{\mathrm{y}}$ is the yield stress and $\eta_{\mathrm{p}}$ is the plastic viscosity. However, the flow curves of the NC suspensions showed a superior fit to the Herschel-Bulkley model [23], which has been used previously to describe the flow behaviour of CNT suspensions [22,24]. The model is a yield-Power Law model, given as:

$$
\tau=\tau_{y}+K \dot{\gamma}^{n}
$$

Where $\mathrm{n}$ and $\mathrm{K}$ are the flow behaviour and consistency indices of the Power-Law model, respectively.

Table 1: Results from data fitting to the Bingham and Herschel - Bulkley models.

\begin{tabular}{|l|l|l|l|l|}
\hline \multicolumn{5}{|l|}{ Bingham Model (SG6_3 suspensions) } \\
\hline CNT / wt. \% & Yield stress, $\tau_{\mathrm{y}} / \mathrm{Pa}$ & Plastic viscosity, $\eta_{\mathrm{p}} / \mathrm{Pa} . \mathrm{s}$ & $\mathrm{R}^{2}\left(\dot{\gamma} \leq 200 \mathrm{~s}^{-1}\right)$ \\
\hline 0 & 0.01 & 15.0 & 0.99 \\
\hline 0.17 & 0.01 & 12.5 & 0.98 \\
\hline 0.33 & 0.09 & 14.6 & 0.99 \\
\hline 1.65 & 0.10 & 16.7 & 0.99 \\
\hline Herschel - Bulkley Model (NC suspensions) & \multicolumn{2}{l|}{} \\
\hline CNT/ wt. \% & Yield stress, $\tau_{\mathrm{y}} / \mathrm{Pa}$ & $\mathrm{n}$ & $\mathrm{K} / \mathrm{Pa} . \mathrm{s}$ & \\
\hline 0.17 & 32.1 & 0.85 & 26.3 & 0.90 \\
\hline 0.33 & 204 & 0.78 & 41.3 & 0.91 \\
\hline
\end{tabular}

For both the epoxy resin and SG6_3 suspensions (Table 1), the values of $\tau_{\mathrm{y}}$ are $\leq 0.1 \mathrm{~Pa}$, indicating essentially Newtonian flow behaviour up to shear rates of approximately $200 \mathrm{~s}^{-1}$. The Herschel - Bulkley model was found to fit the NC suspensions over the full range of experimental shear rate. Compared to the neat resin (Table 1), $\tau_{\mathrm{y}}$ increases by up to three and four orders of magnitude for the 0.17 wt. $\%$ and 0.33 wt. \% NC suspensions, respectively. The results once again show that the incorporation of the hybrid SG6_3 particles does not alter significantly the flow behaviour of the epoxy resin up to the highest loading studied (1.65 wt. \% of grafted CNTs); whilst the addition of only 0.17 wt. \% non-grafted CNTs results in a dramatic change due to the formation of an elastic percolated network 

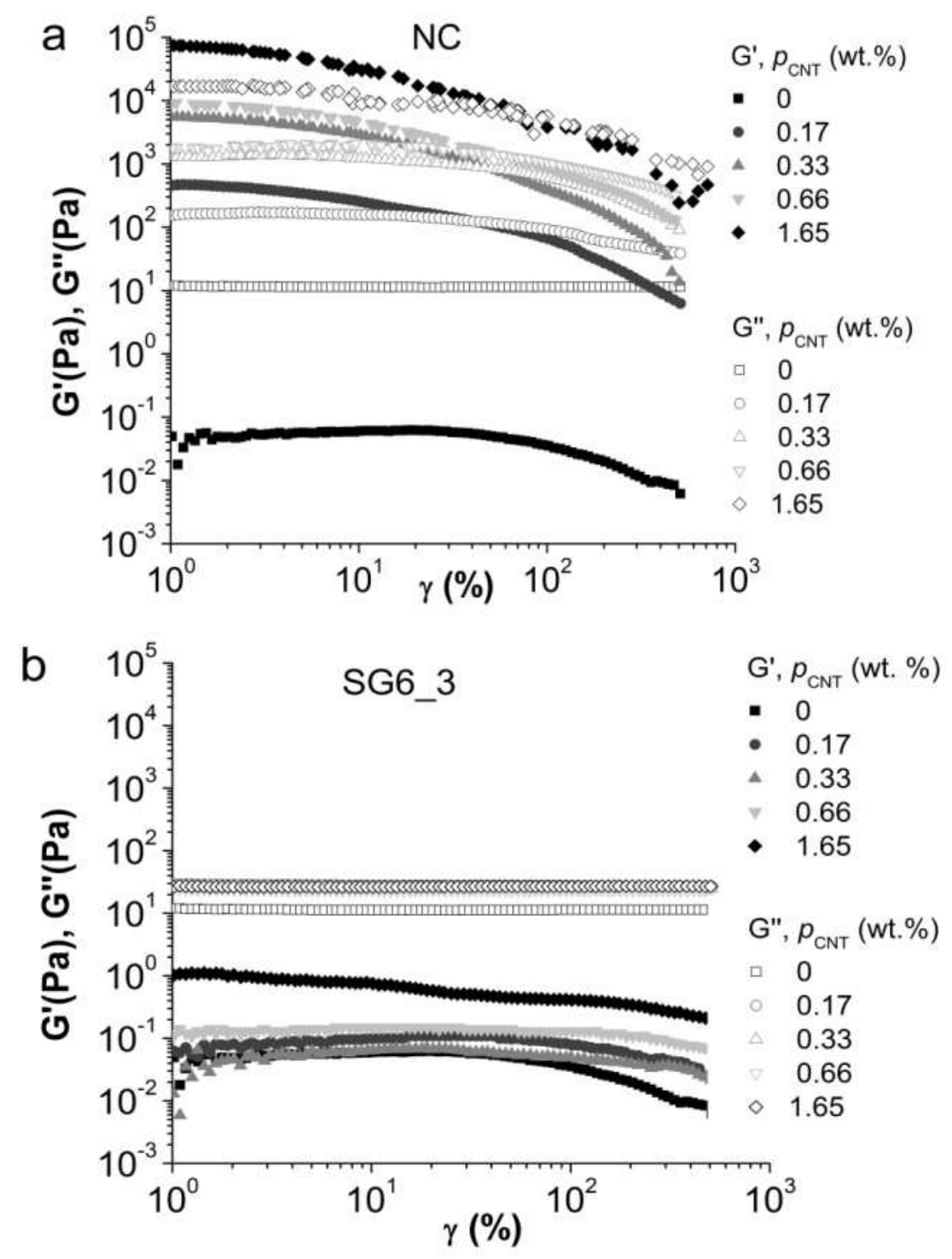

Figure 5. Oscillatory shear measurements conducted at a fixed frequency of $1 \mathrm{rad} / \mathrm{s}$, showing the variation of $G^{\prime}$ and $G^{\prime \prime}$ with strain for the (a) NC and (b) SG6_3 suspensions. The wt. \% shown is that of the grafted CNT in the suspension.

\subsection{Dynamic Shear Properties}

The strain sweep data in Figure 5a show that for all loadings of CNTs in the NC suspensions at low strain $\mathrm{G}^{\prime}>\mathrm{G}^{\prime \prime}$. However, at strains in the region of $30 \%$ modulus crossover occurs as the suspensions undergo a solid-liquid transition, after which $G^{\prime \prime}>G^{\prime}$ indicating predominantly viscous behaviour of the suspensions from this point [25, 26]. Hough et al. [25] observed similar behaviour for aqueous suspensions of SWCNT, which the authors proposed was due to network destruction as the nanotubes rotated through angles large enough to induce separation. The incorporation of CNTs is observed to have significant effects on the epoxy resin, with only 0.17 wt. \% increasing $\mathrm{G}^{\prime \prime}$ by an order of magnitude and $\mathrm{G}^{\prime}$ by four orders. In contrast, for the SG6_3 suspensions their moduli-strain profiles are similar to the epoxy resin in that $\mathrm{G}^{\prime \prime}>\mathrm{G}^{\prime}$ for all of the strain range studied (Figure $5 \mathrm{~b}$ ), showing predominantly viscous 
behaviour. In addition, compared to the NC suspensions there are only relatively small increases in $\mathrm{G}^{\prime}$ values of $\leq$ one order of magnitude for up to $0.66 \mathrm{wt} . \% \mathrm{CNT}$ whilst the corresponding $\mathrm{G}^{\prime \prime}$ values exhibit only a 2-3 fold increase with the addition of the SG6_3 particles. No modulus crossover was observed at any loading, again indicating that the grafted CNTs do not form an elastic, percolated network in these resin suspensions.
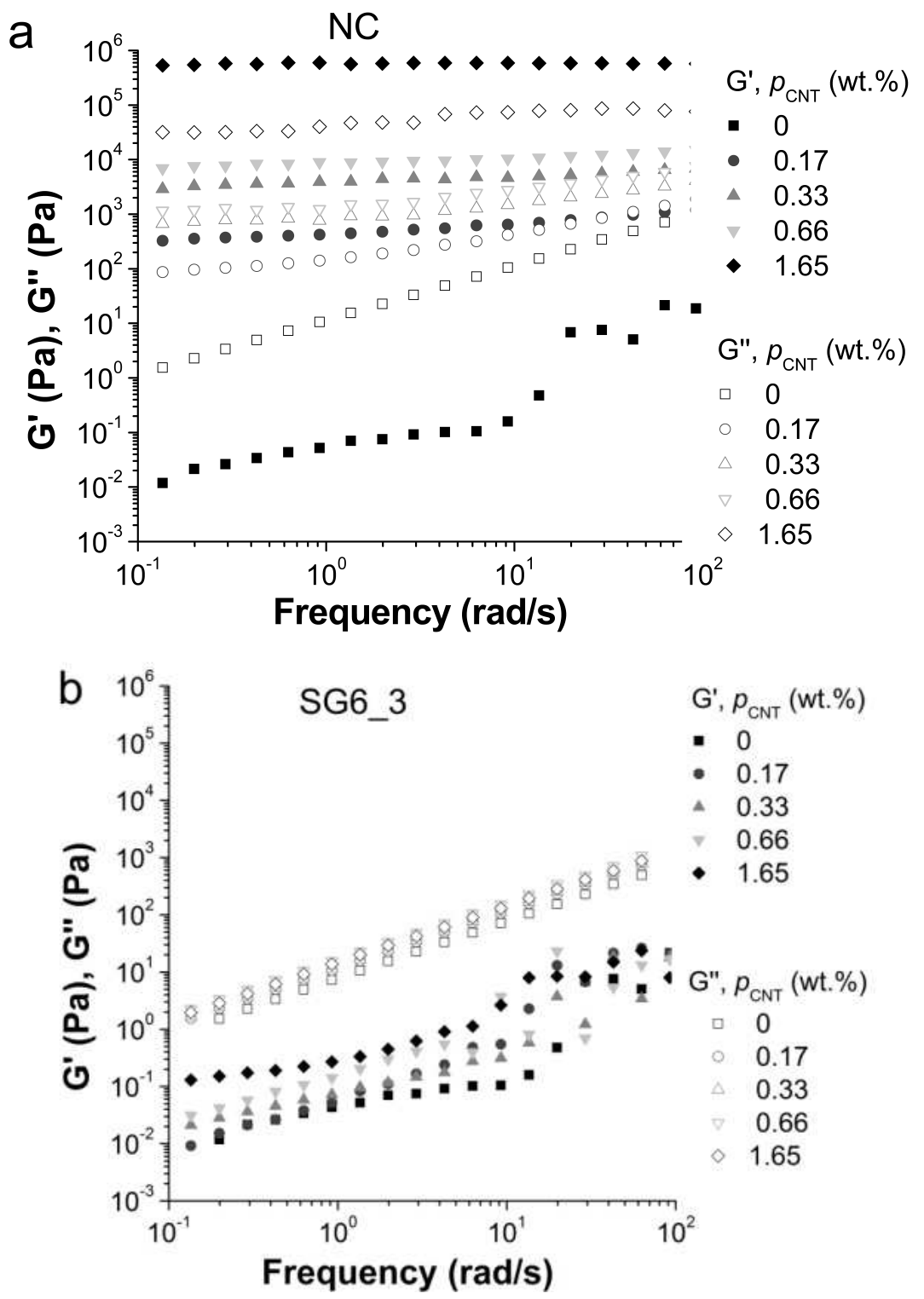

Figure 6. Frequency sweep measurements conducted within LVR, showing $G^{\prime}$ and G' versus frequency for (a) NC and (b) SG6_3-suspensions. The wt. \% shown is that of the grafted CNT in the suspension.

The frequency sweep data in Figure 6 show that for the NC suspensions (Figure 6a), the values of $\mathrm{G}^{\prime}$ and $\mathrm{G}^{\prime \prime}$ within the LVR are almost constant throughout the frequency range studied. The difference is more pronounced at higher CNT loading and for suspensions with > 0.33 wt. \% at all frequencies $G^{\prime}>G^{\prime \prime}$. Similar modulus behaviour, which is typical of a strong gel [22], has been reported for other CNT 
suspension [21, 22, 27]. In the case of SG6_3 suspensions, G" always dominates $G^{\prime}$ (Figure 6b) indicating that these suspensions exhibit only viscous behaviour even at a CNT loading of 1.65 wt. \%.

The advantages of grafting are further demonstrated in Figure 7. As an elastic network does not form in the SG6_3 suspensions, their viscosity remains constant with values similar to those of the neat resin. In contrast, it has been shown that CNTs interact strongly with each other and create an elastic network even at low loadings $[20,22,26]$. Thus, incorporation of only $1.65 \mathrm{wt} . \%$ of CNTs increases $\eta^{*}$ at $1 \mathrm{rad} / \mathrm{s}$ by two orders of magnitude, and the decrease in $\eta^{*}$ values with increasing frequency may be related to a progressive disruption of the percolated CNT network.

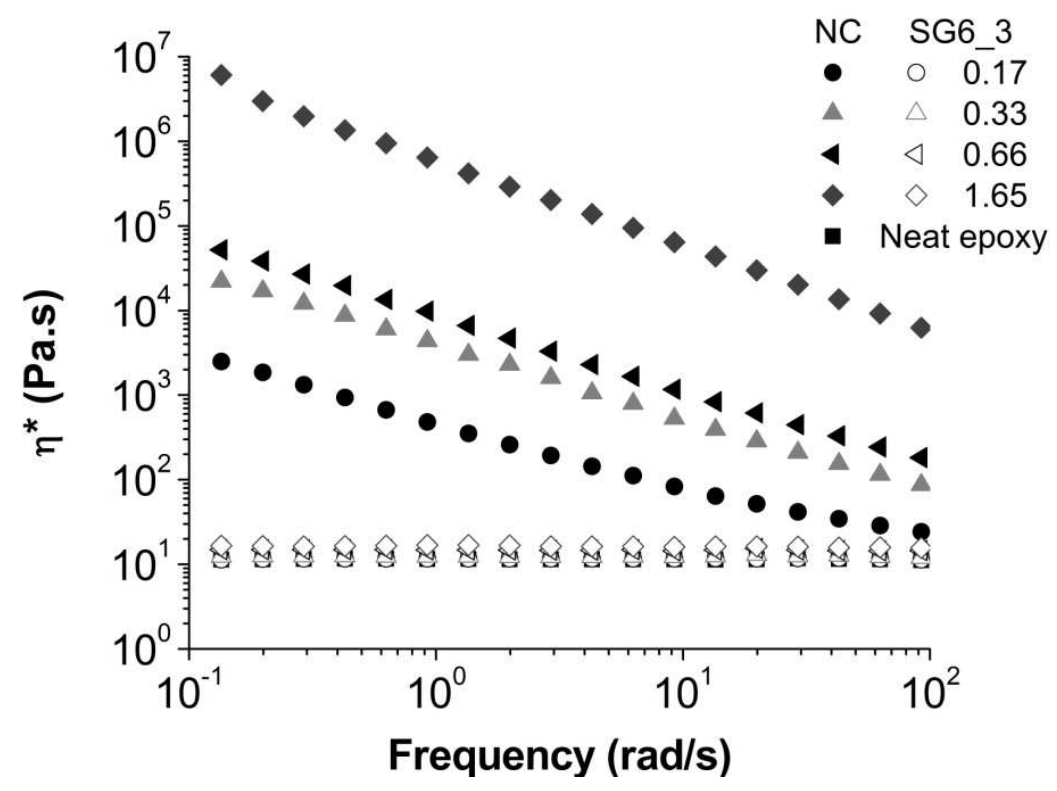

Figure 7. The frequency dependency of complex viscosity, $\eta^{*}$, of the NC and SG6_3 suspensions. The wt. \% shown is that of the grafted CNT in the suspension.

\subsection{Rheological and electrical percolation thresholds}

Figure 8a contrasts the shear moduli variations with particle loading for both suspensions at a fixed frequency. Consistent with previous findings the $G^{\prime}$ and $G^{\prime \prime}$ data for the SG6_3 suspensions show little change with increased loading, as power law behaviour is not observed (both exponents $<1$ ). In contrast, the $G^{\prime}$ and $G^{\prime \prime}$ data for the NC suspensions increase significantly with CNT loading. The measured exponent values of 3.05 and 2.43, respectively, are close to the values of 2.6 and 2.4 reported by Kinloch et al. [22] for aqueous CNT suspensions, indicating similar development in the structure of the CNT network as loading increases. 

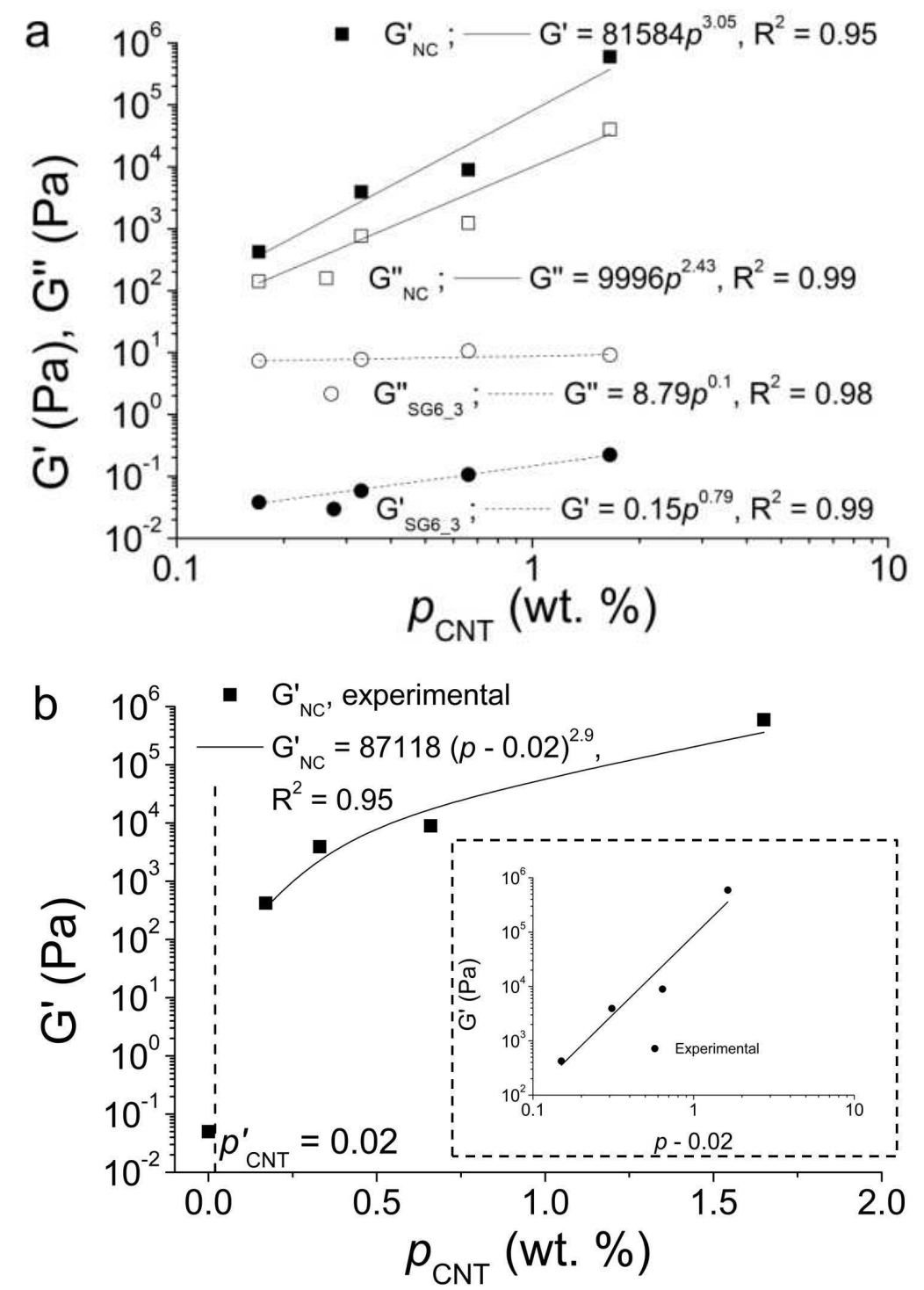

Figure 8. (a) Log - $\log$ plot showing $G^{\prime}$ and $G^{\prime \prime}$ as a function of CNT loading (within the LVR at a frequency of $1 \mathrm{rad} / \mathrm{s}$ ) for both suspensions, the fits shown demonstrate the power law dependency for each modulus. (b) Semi log plot of $G^{\prime}$ (within the LVR at a frequency of $1 \mathrm{rad} / \mathrm{s}$ ) for NC based suspensions as a function of CNT loading. The inset shows a fit to the equation derived from percolation theory.

The rheological percolation threshold (equation 3) was used to determine the critical CNT loading that initiates a rapid increase in $\mathrm{G}^{\prime}$.

$$
G^{\prime}=G_{0}^{\prime}\left(p_{C N T}-p_{C N T, G \prime}^{\prime}\right)^{t_{r h e o}}
$$

Where $G^{\prime}$ is the storage modulus, $G_{0}^{\prime}$ is the proportionality constant, $p_{C N T}$ is the CNT loading, $p_{C N T, G}^{\prime}$ is the critical CNT loading (from $G^{\prime}$ ), and $t_{\text {rheo }}$ is the rheological exponential constant. Fitting the data gave $p_{C N T, G^{\prime}}^{\prime}=0.02 \mathrm{wt}$. $\%$, and $t_{\text {rheo }}=2.9$ which is within the range reported for space-filling networks of particles of between 2 and 4.5 [23]. Similarly, percolation threshold theory may also be used to 
determine the critical particle loading that causes an insulator-conductor transition in a cured composite, given as:

$$
\sigma=\sigma_{c}\left(p_{C N T}-p_{C N T, \sigma}^{\prime}\right)^{t_{e l e}}
$$

Where $\sigma$ is the specific conductivity of the composite, $\sigma_{\mathrm{c}}$ is the proportionality constant, $p_{C N T, \sigma}^{\prime}$ is the critical CNT loading (from $\sigma$ ), and $t_{\text {ele }}$ is the electrical exponential constant. Fitting yielded values of $p_{C N T, \sigma}^{\prime}$ of 0.03 wt. $\%$ and 0.16 wt. \% for the CNT - epoxy and SG6_3 - epoxy composites, respectively. Thus, not surprisingly, the grafting of CNTs to a substrate inhibits the formation of an electricallyconductive percolated network, as formation relies on the orientation of conductive fillers within a polymer. The CNTs are radially distributed along the surface of the SG6_3 particles, yielding essentially isotropic particles. Whereas, it has been shown experimentally [28] and theoretically [29] that higher electrical conductivity is achieved for anisotropic distributions of CNT compared to isotropic distributions, and that aggregates of CNTs within these distributions are crucial in achieving a conductive percolated network in both epoxy resins [3, 30, 31] and polymer melts [32]. In addition, the difference in aspect ratio between the grafted and non-grafted CNT also plays a role. For example, Hernandez et al. [33] obtained a critical loading of 2.1 vol. \% for carbon nanodiscs compared to 0.4 vol. \% for CNTs of higher aspect ratio. Similarly, Sandler et al. showed that the value of critical loading obtained for a carbon black was at least two orders of magnitude higher than for CNT [3]. It is interesting to note that whilst rheology results show that SG6_3 did not form a percolated network within the uncured epoxy resin at CNT values up to $1.65 \mathrm{wt} \%$, the electrical conductivity data for the cured composites showed that the formation of an electrically conductive, percolated network occurred at a critical CNT loading as low as 0.16 wt. \%. This implies that the SG6_3 particles may aggregate upon addition of hardener to form an electrically conductive percolated network, as indicated in the graphic in Figure 10, whereas without hardener, the particles remain isolated as indicated by the optical micrograph in Figure 2. 

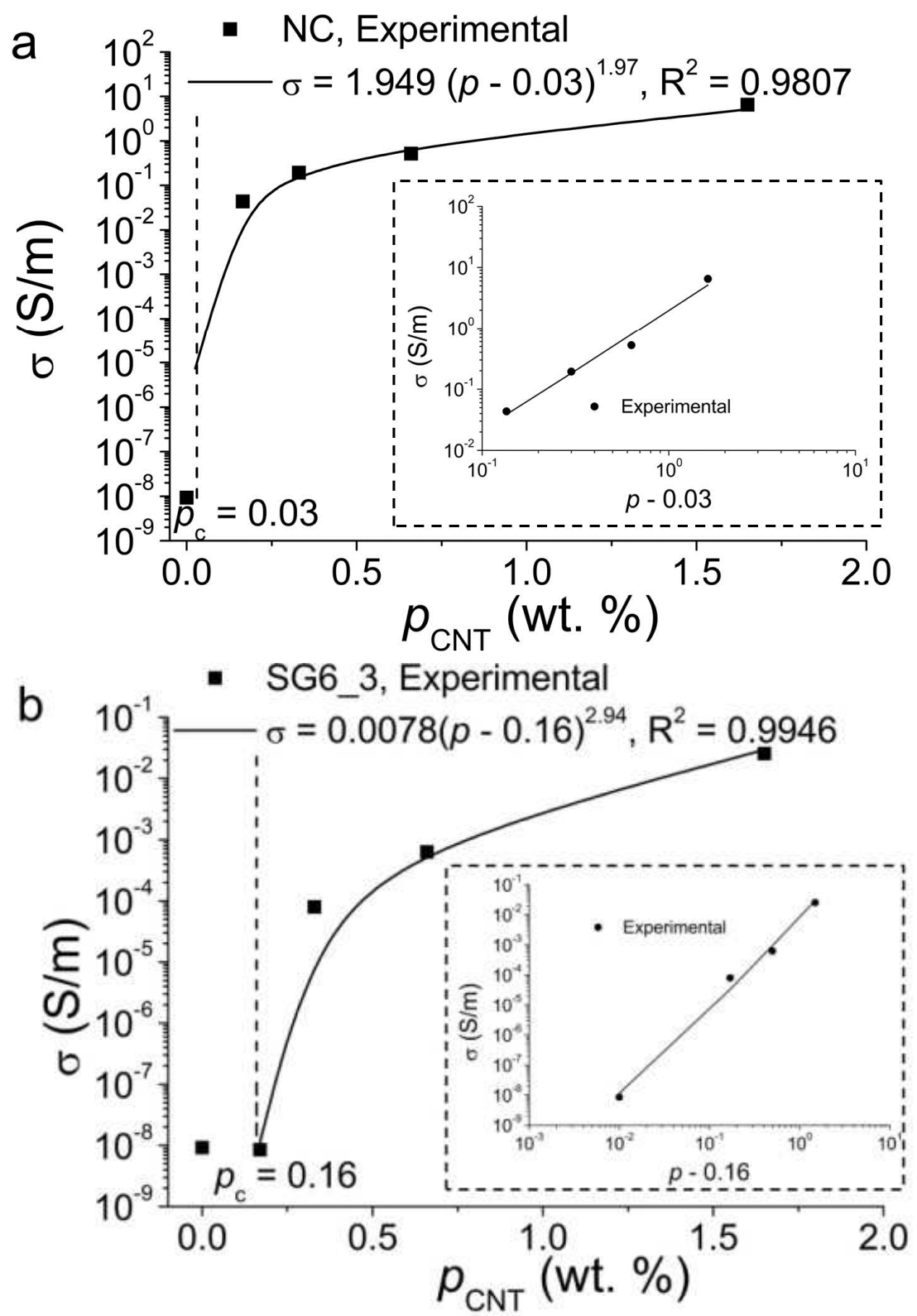

Figure 9. Semi log plot of specific conductivity obtained from (a) NC - epoxy (b) and SG6_3 epoxy composites. The inset showing a fit to the equation derived from percolation theory.

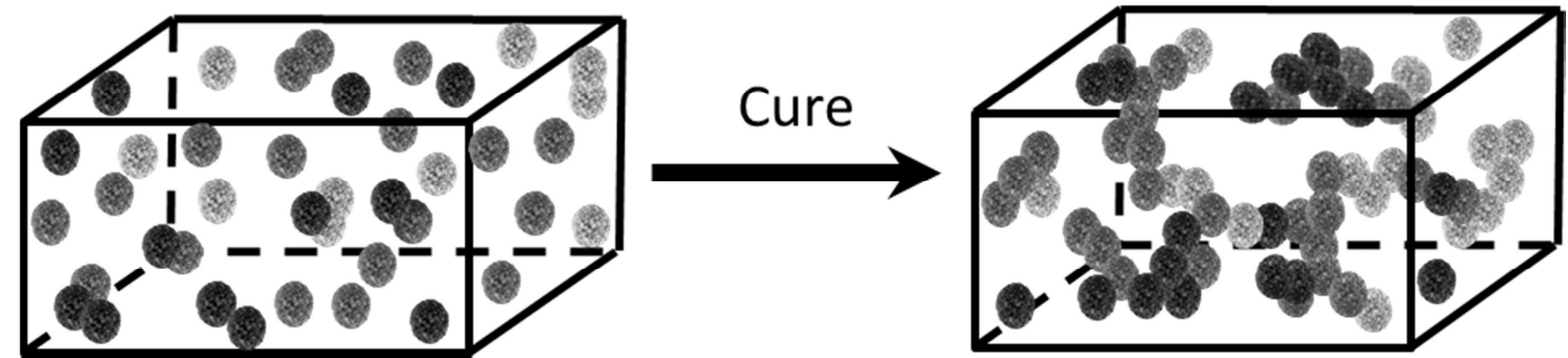

Figure 10. Graphic illustrating the proposed change in particle arrangements in the suspensions for SG6_3; initially showing a dispersed and well distributed suspension with predominantly isolated particles (as indicated by the optical micrograph in Figure 2) which, upon addition of hardener, aggregate to form an electrically conductive percolated network. 


\section{Conclusions}

Suspensions of the SG6_3 particles remained stable during processing, in that application of shear forces during mixing did not detach large numbers of CNTs and the particles did not form aggregates. Up to loadings of 5 wt.\% SG6_3 (1.65\% CNT) the complex viscosity of the suspensions was shown not to change; whereas incorporation of 1.65 wt. \% of non - grafted CNTs increased viscosity by up to five orders of magnitude. In rotational shear, the shear viscosity flow curves of suspensions containing hybrid particles at all loadings followed closely that of the neat resin over a shear rate range of 0.1 to $1000 \mathrm{~s}^{-1}$. In contrast, incorporation of only 0.17 wt. \% non-grafted CNT showed significantly different flow behaviour with the shear viscosity increasing more than an order of magnitude at low shear rates. These differences are ascribed to the lack of interaction of the CNTs grafted on the surface of a SG6_3 particle with those on adjacent particles, whilst the non-grafted CNTs are of much higher high aspect-ratio and exhibit strong inter-tube interactions. In contrast to their rheological behaviour in resin suspensions, the SG6_3 particles formed electrically percolated networks within cured composites at reasonably low loadings ( $\geq 0.16$ wt.\% of CNTs). Thus, the study reported here has demonstrated a practical method to both control the dispersion of CNT into polymer matrices and to introduce CNTs without adversely affecting rheological behaviour.

\section{References}

1. Coleman JN, Khan U, Blau WJ, Gun'ko YK. Small but strong: A review of the mechanical properties of carbon nanotube-polymer composites. Carbon. 2006;44(9):1624-52.

2. Bauhofer W, Kovacs JZ. A review and analysis of electrical percolation in carbon nanotube polymer composites. Compos Sci Technol. 2009;69(10):1486-98.

3. Sandler JKW, Kirk JE, Kinloch IA, Shaffer MSP, Windle AH. Ultra-low electrical percolation threshold in carbon-nanotube-epoxy composites. Polymer, 2003; 44: 5893-99.

4. Xie XL, Mai YW, Zhou XP. Dispersion and alignment of carbon nanotubes in polymer matrix: A review. Materials Science \& Engineering R-Reports. 2005;49(4):89-112.

5. Zhang Q, Liu, Sager R, Dai L, Baur J. Hierarchical composites of carbon nanotubes on carbon fiber: Influence of growth condition on fiber tensile properties. Composites Science and Technology. 2009; 69 (5): 594-601. 
6. Qian H, Bismarck A, Greenhalgh ES, Kalinka G, Shaffer MSP. Hierarchical composites reinforced with carbon nanotube grafted fibers: The potential assessed at the single fiber level. Chem Mat. 2008;20(5):1862-9.

7. Qian H, Bismarck A, Greenhalgh ES, Shaffer MSP. Synthesis and characterisation of carbon nanotubes grown on silica fibres by injection CVD. Carbon. 2010;48(1):277-86.

8. Yamamoto N, Hart AJ, Garcia EJ, Wicks SS, Duong HM, Slocum AH, et al. High-yield growth and morphology control of aligned carbon nanotubes on ceramic fibers for multifunctional enhancement of structural composites. Carbon. 2009;47(3):551-60.

9. I Huang SM. Growing carbon nanotubes on patterned submicron-size $\mathrm{SiO} 2$ spheres. Carbon. 2003;41(12):2347-52.

10. Agrawal S, Kumar A, Frederick MJ, Ramanath G. Hybrid microstructures from aligned carbon nanotubes and silica particles. Small. 2005;1(8-9):823-6.

11. Xiang R, Luo G, Qian W, Wang Y, Wei F, Li Q. Large area growth of aligned CNT Arrays on spheres: towards large scale and continuous production. Chemical Vapor Deposition. 2007;13:533-6.

12. Singh C, Shaffer MS, Windle AH. Production of controlled architectures of aligned carbon nanotubes by an injection chemical vapour deposition method. Carbon. 2003;41(2):359-68.

13. Bozlar M, He DL, Bai JB, Chalopin Y, Mingo N, Volz S. Carbon Nanotube Microarchitectures for Enhanced Thermal Conduction at Ultra low Mass Fraction in Polymer Composites. Adv Mater. 2010;22(14):1654-58.

14. Shui X, Frysz CA, Chung DDL. Electrochemical behavior of hairy carbons. Carbon. 1997;35(10-11):1439-55.

15. Nguyen XH, Lee YB, Lee CH, Lim DS. Synthesis of sea urchin-like particles of carbon nanotubes directly grown on stainless steel cores and their effect on the mechanical properties of polymer composites. Carbon. 2010;48(10):2910-6. 
16. Othman RN, Kinloch IA, and Wilkinson AN. Synthesis and characterisation of silica-carbon nanotube hybrid microparticles and their effect on the electrical properties of poly (vinyl alcohol) composites. Carbon. 2013;60:461-470.

17. Nanocyl. Nanocyl ${ }^{\mathrm{TM}}$ NC 7000 Thin Multiwall Carbon Nanotubes. vol. 2011, 2009.

18. Rahatekar SS, Koziol KKK, Butler SA, Elliott JA, Shaffer MSP, Mackley MR, and Windle AH. Optical microstructure and viscosity enhancement for an epoxy resin matrix containing multiwall carbon nanotubes. Journal of Rheology 2006;50(5):599-610.

19. Seyhan AT, Gojny FH, Tanoglu M, and Schulte K. Rheological and dynamic-mechanical behavior of carbon nanotube/vinyl ester-polyester suspensions and their nanocomposites. European Polymer Journal 2007;43(7):2836-2847.

20. Fan ZH and Advani SG. Rheology of multiwall carbon nanotube suspensions. Journal of Rheology 2007;51(4):585-604.

21. Chapartegui M, Markaide N, Florez S, Elizetxea C, Fernandez M, and Santamaria A. Specific rheological and electrical features of carbon nanotube dispersions in an epoxy matrix. Composites Science and Technology 2010;70(5):879-884.

22. Kinloch IA, Roberts SA, and Windle AH. A rheological study of concentrated acqueous nanotube dispersions. Polymer 2002;43(26):7483-7491.

23. Macosko CW. Rheology Principles, Measurements, and Applications. USA: Wiley-VCH, 1994.

24. Lu K. Rheological behavior of carbon nanotube-alumina nanoparticle dispersion systems. Powder Technology 2007;177(3):154-161.

25. Hough LA, Islam MF, Janmey PA, and Yodh AG. Viscoelasticity of single wall carbon nanotube suspensions. Physical Review Letters 2004;93, 168102.

26. Kayatin MJ and Davis VA. Viscoelasticity and shear stability of single-walled carbon nanotube/unsaturated polyester resin dispersions. Macromolecules 2009;42(17):6624-6632. 
27. Bangarusampath DS, Ruckdaschel H, Altstadt V, Sandler JKW, Garray D, and Shaffer MSP. Rheological and electrical percolation in melt-processed poly(ether ether ketone)/multi-wall carbon nanotube composites. Chemical Physics Letters 2009;482(1-3):105-109.

28. Du FM, Fischer JE, and Winey KI. Effect of nanotube alignment on percolation conductivity in carbon nanotube/polymer composites. Physical Review B 2005;72(12).

29. Behnam A, Guo J, and Ural A. Effects of nanotube alignment and measurement direction ... carbon nanotube films. Journal of Applied Physics 2007;102(4).

30. Martin CA, Sandler JKW, Shaffer MSP, Schwarz MK, Bauhofer W, Schulte K, and Windle AH. Formation of percolating networks in multi-wall carbon-nanotube-epoxy composites. Composites Science and Technology 2004;64(15):2309-2316.

31. Bauhofer W, Schulz SC, Eken AE, Skipa T, Lellinger D, Alig I, Tozzi EJ, and Klingenberg DJ. Shear-controlled electrical conductivity of carbon nanotubes networks suspended in low and high molecular weight liquids. Polymer 2010;51(22):5024-5027.

32. Skipa T, Lellinger D, Saphiannikova M, and Alig I. Shear-stimulated formation of multi-wall carbon nanotube networks in polymer melts. Physica Status Solidi B-Basic Solid State Physics 2009;246(11-12):2453-2456.

33. Hernandez YR, Gryson A, Blighe FM, Cadek M, Nicolosi V, Blau WJ, Gun'ko YK, and Coleman JN. Comparison of carbon nanotubes and nanodisks as percolative fillers in electrically conductive composites. Scripta Materialia 2008;58(1):69-72. 